Expression of Concern

\title{
Expression of Concern on "Andrographolide Enhances Proliferation and Prevents Dedifferentiation of Rabbit Articular Chondrocytes: An In Vitro Study"
}

\author{
Evidence-Based Complementary and Alternative Medicine
}

Received 20 August 2020; Accepted 20 August 2020; Published 25 January 2021

Copyright (C) 2021 Evidence-Based Complementary and Alternative Medicine. This is an open access article distributed under the Creative Commons Attribution License, which permits unrestricted use, distribution, and reproduction in any medium, provided the original work is properly cited.

Evidence-Based Complementary and Alternative Medicine would like to express concern with the article titled "Andrographolide Enhances Proliferation and Prevents Dedifferentiation of Rabbit Articular Chondrocytes: An In Vitro Study" [1]. The authors contacted the journal to say they found several errors due to the wrong placement of samples and that Figures 4 and 6 should be changed. However, they did not provide details, and the authors could not be contacted following this. We are contacting the authors' institution to request that they investigate these concerns.

In addition, the authors did not compare their findings to their related research [2].

\section{References}

[1] L.-k. Luo, Q.-j. Wei, L. Liu, L. Zheng, and J.-m. Zhao, "Andrographolide Enhances Proliferation and Prevents Dedifferentiation of Rabbit Articular Chondrocytes: An In Vitro Study," Evidence-Based Complementary and Alternative Medicine, vol. 2015, Article ID 984850, 10 pages, 2015.

[2] H. Huang, Q. Liu, L. Liu, H. Wu, and L. Zheng, "Effect of epigallocatechin-3-gallate on proliferation and phenotype maintenance in rabbit articular chondrocytes in vitro," Experimental and Therapeutic Medicine, vol. 9, no. 1, pp. 213-218, 2015.

[3] L.-k. Luo, Q.-j. Wei, L. Liu, L. Zheng, and J.-m. Zhao, “Corrigendum to "andrographolide enhances proliferation and prevents dedifferentiation of rabbit articular chondrocytes: an in vitro study", Evidence-Based Complementary and Alternative Medicine, vol. 2020, 2020. 